\title{
Impact of Physical Working Conditions on Operational Level Employees' Job Satisfaction: Case Study of Selected Manufacturing Companies in Sri Lanka
}

\author{
Geethika, THG and Chandrika, KAC
}

\begin{abstract}
Area of the Study

As a significant determinant of job satisfaction of employees, this study is to discuss the impact of physical working conditions on job satisfaction of operational level employees in the selected manufacturing companies in Sri Lanka.

\section{Problem of the Study}

There is an empirical and theoretical knowledge gap of how physical working conditions impact job satisfaction of the operational level employees in the selected manufacturing companies in Sri Lanka.
\end{abstract}

\section{Method of the Study}

The data were collected from a convenient sample of 70 operational level employees in selected manufacturing companies in Sri Lanka with a structured questionnaire, which consisted of 44 questions/statements with five point Likert scale. The data analyses included the univariate and bivariate analyses.

\section{Findings of the Study}

The findings of the study are that there is neither positive nor negative relationship between physical working conditions and the job satisfaction of operational level employees in the selected manufacturing companies in Sri Lanka. As per the regression analysis, physical working conditions have significantly explained $1.5 \%$ of the variance of job satisfaction.

\section{Conclusion of the Study}

It is concluded that physical working conditions should be considered to maintain the satisfaction level of operational level employees in the selected manufacturing companies in Sri Lanka. However, there is no divergence of the impact of physical working conditions on job satisfaction of operational level employees in the selected manufacturing companies in Sri Lanka.

Keywords: Physical Working Condition, Job Satisfaction, Operational Workers

\section{Introduction}

People are the greatest and the most valuable asset to any organization (Danica \&Tomislav 2013). Qualified and motivated people create and deliver value out of other organizational resources (e.g. financial, physical and technology) (Risto et al. 2009). Human Resource Management is related to the management of people of an organization. Today all the organizations in the world have to face to a huge competition. In that situation, Human Resource Management plays a major role in achieving overall organizational goals and objectives. In that case job satisfaction is a one of the major concepts in HRM nowadays (Jagodaarachchi 2014). One dimension that can be taken to evaluate job satisfaction is 
working conditions in the work place. Here, the attempt is to get a better understanding regarding the physical aspects of work environment, which influences job satisfaction of workers in achieving the organizational objectives. To achieve those objectives the best human resource management practices should be there. It largely affects the satisfaction of employees.

\section{Problem Background and Problem of the Study}

In the Sri Lankan context International Labour Organization records around 4,000 workplace accidents and over 80 Sri Lankans loose their lives in work-related accidents every year according to the Labour Department and International Labour Organization (LankaNewspapers.com 2014). About 1,800 work-related accidents are reported in Sri Lanka annually and about 80 of those are fatal accidents. However, these statistics do not reflect the true picture as reporting of occupational accidents is poor in Sri Lanka (Sunday Island 2015). As the Labour Statistics Report (2011), approximately 8.6 million are the working people. Among them the numbers of occupational diseases reported annually were not more than 2,500 to 3,000 and only about 50-60 numbers of fatal occupational accidents were reported (Sunday Observer 2013). The annual loss due to occupational illnesses and accidents is estimated to be 4 percent of the global gross domestic product (GDP) (ILO 2003, as cited in Madurawala 2013).

Hence as explained above, the current awful nature of physical working conditions in the world may be the source of dissatisfaction and occupational hazards, deceases and injuries in workplaces. In other way, employees' job satisfaction may be determined by the degree of physical working conditions of the workplace. Adequate lighting, space, safety, ventilation, noise and coworker relations have an impact of employee attitude towards the organization It is believed that physical working conditions and job satisfaction have a relationship. Physical working conditions appear to have both positive and neither positive nor negative impacts on the job satisfaction of employees. However, there is an unclear idea about physical working conditions and job satisfaction. It seems that there is a gap in empirical evidence, especially in the Sri Lankan context with regard to the impact of physical working conditions on job satisfaction in the apparel industry of operational level employees. Therefore, the problem addressed in this study is to identify whether there is an impact of physical working conditions on operational level employees' job satisfaction in the selected manufacturing companies in Sri Lanka and to examine the nature of the relationship between physical working conditions and job satisfaction of operational level employees in the selected manufacturing companies in Sri Lanka.

\section{Research Framework}

According to Samuel et al. (2013), Arnold and Feldman (1986 as cited in Samuel et al. 2013), Robbins (1998 as cited in Danica \&Tomislav 2013), Kinzl et al. (2005), Ruchi \& Surinder (2014), Juan, Tomas \& Josep (2011), Rashid et al. (2013), Kleiner (1996) \& Statt (1994 as cited in David \& Lauren 2009), Craig, Yu \& Brian (2007), and Bernardi \& Kowaltowski (2006 as cited in Craig, Yu \& Brian 2007) etc there is a positive relationship between 
physical working conditions and employee job satisfaction. Thus, the first hypothesis of this study was as follows:

$\mathrm{H}_{1}$ : If physical working conditions are healthier, then operational level employees' job satisfaction will be at a satisfied level.

According to David \& Lauren (2009), Stefanie et al. (2009), Danica \& Tomislav (2013), Bockerman \& Ilmakunnas (2006 as cited in David \& Lauren 2009), Gretchen \& Melissa (2014), etc. stressed that there is neither positive nor negative relationship between physical working conditions and employee job satisfaction. Thus, the second hypothesis of this study was as follows:

$\mathrm{H}_{2}$ : Physical working conditions positively impact on job satisfaction.

The simultaneous effect of every dimension in independent variable of physical working conditions on job satisfaction of operational level employees is also important to investigate. Therefore, the third hypothesis of this study was formulated as follows:

$\mathrm{H}_{3}$ : Every factor in physical working conditions affect the operational level employees alike.

Relevant schematic diagram is shown in figure 1 below. Job satisfaction of operational level employees is labeled as the dependent variable and physical working conditions are labeled as the independent variable.

Figure 1: Schematic Diagram of the Research Framework

\begin{tabular}{|c|c|}
\hline Physical Working Condition & Job Satisfaction \\
\cline { 2 - 3 }
\end{tabular}

\section{Method}

\section{Study Design}

The type of investigation of this study was a correlation. This was a field study which was conducted in a non-contrived setting with minimal researcher interference to the normal work settings and it was a cross sectional study. No any artificial or contrived setting was created for the study.The unit of analysis was individual where the operational level employees were served as the respondents. The target population of this study was all 323 operational level employees in selected manufacturing companies, including machine operators, production helpers, stores helpers and supervisors. This research study focused on non-probability sampling and for the purpose of the study the researcher only selected 70 operational level employees from the selected company. Sampling technique of this study was convenient sampling, which refers to the collection of information from the members who are conveniently available to provide it.

To collect data as the primary source, a structured questionnaire was used consisting 44 question statements. It was designed with 5 point Likert scale to measure the variables and dimensions in the research model. Data was analyzed using the computer based statistical data analysis package, SPSS version 16.0 for validity, reliability and relationship testing. The 
data analyses have included the univariate and bivariate analyses. The frequency distribution was used to analyze all variables as the descriptive analysis.

\section{Measures}

A questionnaire was used for the data collection of this study. The questionnaire consisted only with close ended question statements. Some of the questions used in this study were well accepted standard questions and the other questions were originally developed by the researcher.

The questionnaire for measuring physical working conditions was a standard questionnaire, which is developed by the European Foundation for the Improvement of Living and Working Conditions (2010), 5th European Survey on Working Conditions and Industrial Accident Prevention Association -2008(López-Alonso \& Oloke 2012), and Lighting at Work Survey. It consisted 20 items, which measured various aspects of the physical working conditions in an organization. The physical working conditions of the selected manufacturing companies were measured in terms of eight dimensions (Arnold et al. 2005) and fourteen indicators as Work sites (Parking area and Location), Workplace design (Ventilation, Air Conditioning system, Canteen and Social relationships), Illumination (Brightness, Glare and Artificial vs. natural light), Noise (Loud noise), Color (Color coding), Temperature \& Humidity (Hot vs. cold environment), Rest Pauses (Authorized breaks) and Shift work (Time period). Those conditions were measured by operational level employees' responses to the questionnaire with Five Point Likert Scale which ranged from 'strongly agree, agree, neither disagree nor agree, disagree and strongly disagree' with points of 5 to 1 respectively for positive statements in the questionnaire and 1 to 5 in reverse order respectively for negative statements in the questionnaire. Question statements numbers 1, 5, 6, 7, 8, 9, 10, 11, 13, 15, 16, 19 and 20 were positive statements and question numbers $2,3,4,12,14,17$ and 18 were negative statements in the questionnaire.

The questionnaire for measuring job satisfaction is known as Minnesota Satisfaction Questionnaire (MSQ), which was originally developed by Weiss, Dawis, England \& Lofquistin 1967 was used to measure the job satisfaction. It also contained 20 items which measured various aspects of the job satisfaction of operational level employees. Job satisfaction was measured in terms of nine dimensions (Jagodaarachchi 2014) and fourteen indicators as Health \& Safety (Hazards), Job nature (Achievement, Workload, Responsibility, Cooperation and Supervisor - subordinate relations), Job security (Moral value), Promotion (Advancement), Pay (Compensation), Working groups (Co-workers), Welfare (Improvement), Use of skills \& abilities (Optimization and Motivation) and Management style \& culture (Socialization). Job satisfaction of operational level employees was measured by operational level employees' responses to the questionnaire with Five Point Likert Scale.It was ranged from 'very satisfied, satisfied, neithersatisfied nor dissatisfied, dissatisfied and very dissatisfied' with points of 5 to 1 respectively for positive statements in the questionnaire. 


\section{Validity and Reliability}

The external reliability of the instruments used to collect data was examined by Test - retest test method. The internal item consistency reliability was examined with Cronbach's Alpha Coefficient test (Kottawatta 2014). The results of test - retest coefficient and Cronbach's Alpha test are given in Table 1 below, which suggests that the external and internal reliability of each instrument was satisfactory.

Table 1: Results of Test - Retest

\begin{tabular}{|l|l|c|c|}
\hline & Instrument & Test - retest Coefficient & Cronbach's Alpha \\
\hline 1 & Physical Working Conditions & 0.819 & 0.778 \\
\hline 2 & Job Satisfaction & 0.796 & 0.7145 \\
\hline
\end{tabular}

The content validity of the instruments was ensured by the conceptualization and operationalization of the variables based on the literature, and indirectly by the high internal consistency reliability of the instruments as denoted by Cronbach's Alpha (Kottawatta 2014). The construct validity of the variables of the study was ensured by the fact that the correlation and regression analysis support the hypotheses formulated linking the relationship between the independent variable and the dependent variable (Kottawatta 2014).

\section{Techniques of Data Analyses}

Data collected from primary sources (questionnaire) were analyzed using the computer based statistical data analysis application, SPSS (version 16.0) for validity, reliability, and relationship testing. The data analysis included univariate and bivariate analyses.

\section{Results}

Univaraite analysis was used to investigate the responses for independent and dependent variables of the operational level employees in the selected manufacturing companies. The results of the univariate analysis are depicted in the table 2 below.

Table 2: Univariate Analysis

\begin{tabular}{|l|r|r|}
\hline \multirow{2}{*}{ Valid } & \multicolumn{2}{|c|}{ Operational level employees } \\
\cline { 2 - 3 } & PWC & \multicolumn{1}{c|}{ JS } \\
\hline Mean & 70 & 70 \\
\hline Median & 3.5515 & 3.5377 \\
\hline Mode & 3.5490 & 3.5648 \\
\hline Std. Deviation & 3.69 & 3.67 \\
\hline Variance & .21425 & .27733 \\
\hline Skewness & .046 & .077 \\
\hline Std. Error of Skewness & -.177 & .020 \\
\hline Kurtosis & .287 & .287 \\
\hline Std. Error of Kurtosis & -.334 & -.364 \\
\hline Minimum & .566 & .566 \\
\hline
\end{tabular}




\begin{tabular}{|l|r|r|}
\hline Maximum & 4.05 & 4.23 \\
\hline
\end{tabular}

According to the table 2 above, the level of perceived physical working conditions in the selected manufacturing companies is negatively distributed and the perceived level of job satisfaction of operational level employees is approximately normally distributed.

The bivariate analysis included Pearson's Product Movement Correlation and Simple Regression analysis. The Pearson's correlation between physical working conditions and job satisfaction of operational level employees in the selected manufacturing companies is illustrated in table 3 below.

Table 3: The Pearson's Correlation between Independent Variable and Dependent Variable

\begin{tabular}{|l|r|}
\hline & Operational Level Employees \\
\hline Pearson Correlation & -.007 \\
\hline Sig. (1-tailed) & .476 \\
\hline $\mathrm{N}$ & 70 \\
\hline
\end{tabular}

According to the results of the Pearson's Correlation shown in the table 3 above, there is a negative but not an extremely negative $(\mathrm{r}>-0.5)$ relationship between physical working conditions and job satisfaction of operational level employees. The Pearson Correlation between two variables is -0.007 , which is almost near to the 0 (zero). It shows that there is neither negative nor positive relationship between physical working conditions and job satisfaction of operational level employees in the selected manufacturing companies.

Regression analysis was made to investigate the functional relationship between two variables and it is given in Table 4 below.

Table 4: Results of Regression Analysis

\begin{tabular}{|l|c|}
\hline Variable & Physical Working Conditions \\
\hline Method & Linear \\
\hline R Square & 0.049 \\
\hline Adjusted R Square & 0.015 \\
\hline F & 0.004 \\
\hline Significance & 0.951 \\
\hline B-constant & 3.572 \\
\hline b-value & -0.010 \\
\hline
\end{tabular}

The gradient of the regression, which means the $b$ value of the equation is -0.010 , which is significant at $1 \%$ (significant $=0.000$ ). The $\mathrm{R}$ Square statistic is a measure of the strength of association between the observed and predicted values of the dependent variable of the study. The small R Square value 0.049 indicates a less strong relationship. With the $1.5 \%$ of $\mathrm{R}$ Squared of the variance of job satisfaction is explained by physical working conditions with the standardized beta of 0.049 . The $\mathrm{F}$ value is 0.004 , which is significant at $1 \%(\mathrm{p}=0.000)$. It suggests that physical working conditions have significantly explained $1.5 \%$ of the variance 
of job satisfaction. Therefore, the independent variable neither positively nor negatively related with the dependent variable.

\section{Discussion and Conclusion}

According to the results of Pearson's correlation analysis, it was found that there is neither positive nor negative relationship between physical working conditions and job satisfaction of operational level employees in the selected manufacturing companies. The findings of correlation and regression analysis empirically confirm the argument given by Herzberg in 1959. He has identified working conditions as a 'hygiene factor'. Factors that involve in job context (hygiene factors) tend to lead to job dissatisfaction (Robert \& Lawrence n.d.). But when these factors are good or acceptable, workers do not become "satisfied", they simply become "not dissatisfied". Therefore, as indicated by the empirical data, job satisfaction of operational level employees in the selected manufacturing companies did not depend on physical working conditions of the organization.

As the statistical evidences indicated, all the hypotheses were accepted. The first hypothesis was: if physical working conditions are healthier, then operational level employees' job satisfaction will be at a satisfied level.It was confirmed that job satisfaction of operational level employees in the selected manufacturing companies is in a satisfied level due to the acceptable condition of physical working conditions. The second hypothesis was: there is a relationship between physical working conditions and job satisfaction. The statistical evidences supported to accept the hypothesis. The third hypothesis was: every factor in physical working conditions affect to operational level employees alike. It was confirmed to accept the hypothesis developed, since all the respondents got an average value (mean value) for each factor of physical working conditions. The sample consisted of 39 male and 31 female respondents and the mean value of the physical working conditions was 3.5515 for all respondents.

Although the findings revealed that there is neither positive nor negative relationship between physical working conditions and job satisfaction, the fulfillment of the legal obligations of the working conditions is a must. It is advisable, therefore, to give a high concentration on basic physical working conditions such as workplace design, temperature, noise, illumination, color and color coding, shift work and rest pauses, as they may affect the health of employees. Although there is not a dissatisfaction level regarding the physical working conditions, it is better to continuously improve the physical working conditions and give a due consideration on that to maintain the satisfaction level of employees. The education level, awareness and family background of employees may have an impact on the findings of this study, as operational level employees are the lower cluster of the selected company. Therefore,it is better to provide an awareness program to increase the knowledge of employees regarding the current physical working conditions in the selected manufacturing companies and the impact of that on the health conditions of them.

In addition to above recommendations, as a major way of enhancing job satisfaction of operational level employees, the programs related to the improvement of job satisfaction are 
to be implemented successfully. Ensuring health and safety, job nature, job security, promotion, fair pay and compensation, nature of the working groups, welfare facilities, use of skills \& abilities of employees and management style \& culture of the organization (Jagodaarachchi, 2014) are the few ways of upgrading the job satisfaction of a worker.

The researchers believe that the important variables may account for the unexplained variable in the job satisfaction of operational level employees may be the psychological and social factors (Arnold et al. 2005) such as job simplification, boredom, monotony, ethnic harassment, gender harassment and so on.Further research studies are suggested to establish the importance of these factors on job satisfaction to find out the impact and the nature of the relationship with all employees including operational level employees, managerial and nonmanagerial employees not only in one organization, but in several different scale organizations with a larger sample. It is essential to have a better instrument developed in the Sri Lankan context in order to reduce the difficulties encountered in measuring the variables.

\section{References}

i. Arnold, J, Joanne, S, Fiona, P, Ivan, R, Cary, C \& Bernard, B 2005, Work Psychology - Understanding Human Behavior in the Workplace', 4th edition, Prentice Hall, pp. $292-310$.

ii. Craig, L, Yu, S \& Brian, P 2007, 'Perceived Conditions of Workers in Different Organizational Settings', Facilities, Vol. 26, No. 2, pp. 54 - 62.

iii. Danica, B \& Tomislav, B 2013, 'Relationship between Working Conditions and Job Satisfaction: The Case of Croatian Shipbuilding Company', International Journal of Business and Social Science, Vol. 4, No. 2, pp. 206 - 209.

iv. David, M \& Lauren, M 2009, 'The Impact of Physical Environment on Employee Commitment in Call Centers', Team Performance Management, Vol. 15, No. 2, pp. $35-42$.

v. European Foundation for the Improvement of Living and Working Conditions 2010, http://discover.ukdataservice.ac.uk/Catalogue/?sn=6971\&type=Data\%20catalogue.

vi. Gretchen, W \& Melissa, B 2014, 'Physical Work Environment in Hospitals Affects Nurses' Job Satisfaction with Implications for Patient Outcomes', Health Care Costs. [online] Available from: www.rwif.org, (Accessed 15/11/2014).

vii. Jagogodaarachchi, B 2014, [online] Available from: http://www.academia. edu/4066547/Research_Project_Employee_Job_Satisfaction, (Accessed 25/10/2014).

viii. Juan, AMG, Tomas, B \& Josep, ML 2011, 'Exploring Working Conditions as Determinants of Job Satisfaction: An Empirical Test among Catalonia Service Workers', The Service Industries Journal, Vol. 31, No. 12, pp. 2052 - 2064.

ix. Kinzl, JF, Knotzer, H, Traweger, C, Lederer, W, Heidegger T \& Benzer, A 2005, 'Influence of working conditions on job satisfaction in an anesthetists', British Journal of Anesthesia, pp. 211 - 215.

x. Kottawatta, H 2014, Research Guide Book, Department of Human Resource Management, Colombo. 
xi. Labour Statistics Report 2011, http://www.labourmin.gov.lk/web/images/stories/publication/other/labour_and_social trends_in\%20srilanka.pdf.

xii. Lanka Newspapers.com. 2014, Sri Lanka News Updates with Discussions. [online] Available from: http://www.lankanewspapers.com/news/2014/1/86306.html, (Accessed 21/02/2015).

xiii. López-Alonso M \& Oloke, D 2012, 'The impact of training on construction industry accidents: A review of the United Kingdom and Spain', Advanced Research in Scientific Areas, Vol. 3, No. 7, pp. 1837-1841.

xiv. Madurawala 2013, Dying to work. [online] Available from: http://www.dailymirror.lk/business/features/36948-dying-to-work-why-health-andsafety-in-workplace-an-important-economic-issue.html, (Accessed 21/02/2015).

xv. Rashid, S, Rab, NL, Anam, I, Hafiza, HN, Shireen, M \& Somia, Y 2013, 'Factors Influencing Job Satisfaction of Employees in Telecom Sector in Pakistan', MiddleEast Journal of Scientific Research, vol. 16, no. 11, pp. 1476 - 1482.

xvi. Risto, K, Ossi, R, Tea, L \& Eero, L 2009, 'Physical and psychosocial working conditions as explanations for occupational class inequalities in self-rated health', European Journal of Public Health, Vol. 19, No. 5, pp. 458 - 460.

xvii. Ruchi, J \& Surinder, K 2014, 'Impact of Work Environment on Job Satisfaction', International Journal of Scientific and Research Publications, Vol. 4, No. 1, pp. 1 - 4.

xviii. Samuel, OM, Jacqueline, LM, Juma, W \& Kabare, K 2013, 'Effects of Organizational Work Conditions on Employee Job Satisfaction in the Hotel Industry in Kenya', International Journal of Arts and Commerce, Vol. 2, No. 2, pp. 79 - 84.

xix. Stefanie, M, Karin, V, Albert, N, Burghard, FK \& David, AG 2009, 'Physicians' working conditions and job satisfaction: does hospital ownership in Germany make a difference?', [online] Available from: http://www.biomedcentral.com/14726963/9/148, (Accessed 15/11/2014).

xx. Sunday Island, 2015, [online] Available from: http://www.island.lk/index.php? page_cat $=$ article-details $\&$ page $=$ article-details $\&$ code_title $=111357, \quad$ (Accessed 21/02/2015).

xxi. Sunday observer 2013, [online] Available from: - http://www.sundayobserver. lk/2013/10/13/spe02.asp, (Accessed 21/02/2015).

xxii. Weiss, DJ, Dawis, RV, England, GW \& Lofquist, LH 1967, 'Manual for the Minnesota Satisfaction Questionnaire', Vol. 22, Minnesota Studies in Vocational Rehabilitation, Minneapolis: University of Minnesota, Industrial Relations Center.

\section{Geethika, THG}

HR Executive, Fantasia Elastics (Pvt) Ltd

gayani65@yahoo.com

\section{Chandrika, KAC}

Senior Lecturer, Department of Human Resource Management, University of Sri Jayewardenepura methashag@gmail.com 